\title{
Social inequality in pre-pregnancy BMI and gestational weight gain in the first and second pregnancy among women in Sweden
}

Natalie Holowko ${ }^{1}$, M. Pia Chaparro ${ }^{2}$, Karina Nilsson ${ }^{3}$, Anneli Ivarsson ${ }^{4}$, Gita Mishra ${ }^{1}$, Ilona Koupil $^{2,5}$, Anna Goodman ${ }^{2,6}$

${ }^{1}$ Centre for Longitudinal and Life Course Research, School of Public Health, University of Queensland, Herston Road, 4006 Brisbane, Australia

${ }^{2}$ Centre for Health Equity Studies (CHESS), Stockholm University/Karolinska Institute, Sveavägen 160, 10691 Stockholm, Sweden

${ }^{3}$ Department of Sociology, Umeå University, SE-901 87, Umeå, Sweden

${ }^{4}$ Department of Public Health and Clinical Medicine, Epidemiology and Global Health, Umeå University, SE-901 87, Umeå, Sweden

${ }^{5}$ Department of Public Health Sciences, Karolinska Institutet, Tomtebodavägen 18A, 17177 Stockholm, Sweden

${ }^{6}$ Faculty of Epidemiology and Population Health, London School of Hygiene and Tropical Medicine, Keppel Street, London WC1E 7HT, United Kingdom.

Corresponding author: Natalie Holowko, C/- Centre for Health Equity Studies (CHESS), Stockholm University/Karolinska Institute, Sveavägen 160, 10691 Stockholm, Sweden (n.holowko@uq.edu.au)

Note: this is a personal version, created by Anna Goodman, of the text of the accepted journal article. It reflects all changes made in the peer review process, but does not incorporate any minor modifications made at the proof stage. The complete citation for the final journal article is:

- Holowko, N., Chaparro, P., Nilsson, K., Ivarsson, A., Mishra, G., Koupil, I. \& Goodman, A. 2015. Social inequality in pre-pregnancy BMI and gestational weight gain in the first and second pregnancy among women in Sweden. Journal of Epidemiology and Community Health, 69, 1154-1161.

- DOI: 10.1136/jech-2015-205598

Copyright $(\subset$ and Moral Rights for this paper are retained by the individual authors and/or other copyright owners 


\section{$\underline{\text { Abstract }}$}

Background: High pre-pregnancy body mass index (BMI) and inappropriate gestational weight gain $(\mathrm{GWG})$ are associated with adverse short and long-term maternal and neonatal outcomes and may act as modifiable risk factors on the path to overweight/obesity, but their social patterning is not well established. This study investigates the association of education with BMI and GWG across two consecutive pregnancies.

Methods: The study includes 163,352 Swedish women, having their first and second singleton birth in 1982-2010. In both pregnancies, we investigated the association of women's education with i) pre-pregnancy weight status and ii) adequacy of GWG. We used multinomial logistic regression, adjusting for child's birth year, mother's age and smoking status.

Results: Overall, the odds of starting either pregnancy at an unhealthy BMI were higher among women with a low education compared to more highly-educated women. Lower education also predicted a greater increase in BMI between pregnancies, with this effect greatest among women with excessive GWG in the first pregnancy $(p<0.0001$ for interaction). Education was also inversely associated with odds of excessive GWG in both pregnancies among healthy weight status women, but this association was absent or even weakly reversed among overweight and obese women.

Conclusion: Lower educated women had the largest BMI increase between pregnancies, and these inequalities were greatest among women with excessive GWG in the first pregnancy. The importance of a healthy pre-pregnancy BMI, appropriate GWG and a healthy postpartum weight should be communicated to all women, which may assist in reducing existing social inequalities in body weight.

Key Words: educational status; socioeconomic position; body mass index; gestational weight gain; social inequalities; pregnancy. 


\section{Highlights}

What is already known on this subject?

- High pre-pregnancy body mass index and excessive gestational weight gain have been associated with adverse short and long-term consequences for mother and child

- In the first pregnancy, low socioeconomic position is associated with high prepregnancy body mass index and excessive gestational weight gain (among women of healthy weight status). Low socioeconomic position is also associated with long term obesity

What this study adds?

- Women with a low education had increased risk of starting their first and second pregnancies at an unhealthy weight and had the greatest increase in body mass index between pregnancies. This association was strongest among women who gained weight excessively in their first pregnancy Among healthy weight women, there was a protective effect of education on excessive gestational weight gain in both pregnancies. Among overweight and obese women, in both pregnancies there was either no significant association between education and gestational weight gain or even a trend in the opposite direction

- Given that gestational weight gain is a modifiable risk factor on the path to overweight/obesity development, ensuring women and practitioners are aware of the most up-to-date guidelines is of priority. 


\section{Introduction}

Obesity increases the risk of chronic disease, and contributes largely to overall disease burden. ${ }^{1}$ While Sweden's prevalence of overweight/obesity is lower than many other high income countries ( $\sim 40 \%$ of women aged $16-84$ years) $)^{2}$ it has increased significantly among all Swedish counties from 1992 to $2010 .^{3}$ This is important since pre-pregnancy obesity and excessive gestational weight gain $(\mathrm{GWG})$ are associated with increased risk of several adverse maternal, neonatal and child outcomes. ${ }^{4,5}$ In addition, the transition to motherhood involves psychological and behavioural changes that may influence future weight, ${ }^{6}$ including through excess GWG and weight retained postpartum. ${ }^{7,8}$

Studies conducted in Australia ${ }^{9,10}$ and the $\mathrm{UK}^{11}$ found greater weight gain over 4 years ${ }^{10}$ and 10 years $^{9,11}$ among parous women compared to nulliparous, with on average $0.3-4.0 \mathrm{~kg}$ extra per pregnancy. ${ }^{11}$ Likewise in Sweden ${ }^{12}$ and the USA, ${ }^{13}$ increasing parity is associated with long-term obesity, with some evidence that this particularly reflects the role of the first pregnancy. ${ }^{14,15}$

In the USA ${ }^{5,16}$ and Europe ${ }^{17}$ excessive GWG is common, particularly among younger women ${ }^{18}$ and women with pre-pregnancy overweight/obesity. ${ }^{11,19}$ For example, one small Swedish study found excessive GWG among $87 \%$ of overweight and $53 \%$ of obese women. ${ }^{19}$ This matters since high GWG is the strongest predictor of post-partum weight retention ${ }^{7,8,14}$, 20-22 and of becoming overweight/obese after pregnancy. ${ }^{21}$ By contrast, pre-pregnancy BMI is positively associated with weight retention in some ${ }^{7,15,22}$ but not all studies. ${ }^{17,23}$ These factors likely interact, with greatest weight retention observed among women with both high pre-pregnancy BMI and excessive GWG. ${ }^{8}$ The risk of repetition in subsequent pregnancies is plausible, ${ }^{24}$ highlighting the importance of accurate GWG advice.

Women with a low socioeconomic position (SEP) are at higher risk of pre-pregnancy overweight/obesity, ${ }^{1,25}$ and this social differential seems to have widened over time among obese individuals in Sweden. ${ }^{26}$ Lower SEP (measured by education or occupation) is also inversely associated with weight retention ${ }^{11,20}$ and long-term BMI in women, ${ }^{9,27,28}$ though less is known about the role of SEP for GWG. A Swedish study of primiparous women found that education was protective of excessive GWG only among women of healthy weight status ${ }^{25}$ while a U.S. study found a protective effect of high SEP that was dependent on race and neighbourhood residence. ${ }^{29}$

While GWG is higher in primiparous than multiparous women, ${ }^{30}$ we know of no studies investigating SEP differences in BMI change or GWG in the first and second pregnancy. Since GWG is a key modifiable risk factor for development of overweight/obesity, understanding the relationship across consecutive pregnancies may reveal whether the risk is further increased in already disadvantaged groups. This study aimed to investigate the association between education and i) women's change in BMI from before the first pregnancy (BMI1) to before the second (BMI2); and ii) gestational weight gain in the first pregnancy $(\mathrm{GWG} 1)$ and in the second $(\mathrm{GWG} 2)$.

\section{$\underline{\text { Methods }}$}


We used data from the Swedish Medical Birth Register and the Education Register, accessed through the Umeå SIMSAM Lab (http://www.org.umu.se/simsam/english/). We focused on the 853,148 women with a first and second singleton birth between 1982 and 2010.

Of these women, 522,581 had pre-pregnancy BMI available for both pregnancies and 196,739 (23\%) also had complete information on GWG1 and GWG2 (weight data not collected in 1990 and 1991). ${ }^{31}$ We excluded 2,029 women with implausible values

(Supplementary File 1), 16,774 with missing education data, and 14,584 with missing data on smoking during pregnancy. This left a study population of 163,352 (19\% of the total population).

In assessing the potential for selection bias, we found similar characteristics in the women excluded due to missing information $(\mathrm{n}=689,796)$ as in our study population $(\mathrm{N}=163,352)$. The only significant differences were small: excluded women had a higher mean BMI1 $\left(\sim 0.4 \mathrm{~kg} / \mathrm{m}^{2}\right.$ higher) and BMI2 $\left(\sim 0.6 \mathrm{~kg} / \mathrm{m}^{2}\right.$ higher $)$ and were slightly more likely to be nonsmokers ( $84 \%$ vs. $81 \%$ in the first pregnancy). Excluded women also had marginally higher education levels (35\% vs. $32 \%$ in the first pregnancy).

\section{Primary exposure - education}

Woman' education was recorded for each index child's birth year, except for births in 19821984, where education was recorded in 1985 since no annual education was available. Education was categorised as low (primary and lower secondary, $\leq 10$ years education), intermediate (upper secondary, $\leq 13$ years education) or high (post-secondary).

\section{Outcome variables - BMI and GWG in the first and second pregnancy}

BMI before the first pregnancy (BMI1) and the second pregnancy (BMI2) were calculated based on height and pre-pregnancy weight. Self-reported/measured pre-pregnancy weight was recorded at registration for antenatal care ( 8-12 weeks gestation) from 1992 onwards, and was calculated by combining self-reported/measured weight at delivery and GWG for women giving birth before $1992^{31}$ (the extent of self-report vs. measured weights is unknown). Based on pre-pregnancy BMI and World Health Organisation (WHO) definitions, ${ }^{32}$ weight status before the first and second pregnancy was categorised as underweight $\left(<18.50 \mathrm{~kg} / \mathrm{m}^{2}\right)$, healthy weight $\left(18.50-24.99 \mathrm{~kg} / \mathrm{m}^{2}\right)$, overweight $(25.00-29.99$ $\left.\mathrm{kg} / \mathrm{m}^{2}\right)$ or obese $\left(\geq 30.00 \mathrm{~kg} / \mathrm{m}^{2}\right)$.

Using the US Institute of Medicine's (IOM) guidelines, we defined adequate GWG as: 12.5$18 \mathrm{~kg}$ for underweight; $11.5-16 \mathrm{~kg}$ for healthy weight; $7-11.5 \mathrm{~kg}$ for overweight; and $5-9 \mathrm{~kg}$ for obese women. ${ }^{33}$ GWG1 and GWG2 were categorised as excessive if above this recommended weight gain, and as inadequate if below. While the IOM guidelines have been criticised in Sweden as being too generous, particularly for overweight/obese women, ${ }^{34}$ to date they remain the only official GWG guidelines. 


\section{Covariates}

For each pregnancy, we obtained data on mother's cigarette smoking as recorded at first antenatal care visit (non-smoker, 1-9 cigarettes/day, 10+ cigarettes/day) and mother's age. The WHO recommends an interval of 18-27 months between a live birth and the next pregnancy, implying an ideal interval around 27-36 months between subsequent births. ${ }^{35} \mathrm{We}$ categorised birth the birth interval between child 1 and 2 as <27, 27-36, 36.1-68, >68 months).

\section{Statistical analyses}

Descriptive statistics explored the association of education and maternal characteristics with the two main outcomes: i) BMI change between pregnancies, stratified by GWG1; and ii) GWG1 and GWG2, stratified by weight status before the pregnancy in question. Multinomial logistic regression investigated social patterning of GWG1 and GWG2 (stratified by weight status). Initially, all were minimally adjusted for the index child's birth year (Model 1), followed by adjustment for mother's age, pre-pregnancy BMI and smoking status (Model 2). Analysis of GWG2 was further adjusted for birth interval in Model 2. We also tested for interactions to see whether the association between education and GWG differed between the two pregnancies.

In supplementary analyses, multinomial logistic regression investigated social patterning of weight status prior to both pregnancies, additionally adjusted for mother's age and smoking status (Model 2). Analysis of weight status prior to the second pregnancy was further adjusted for GWG1 and birth interval (Model 3).

All findings were very similar in sensitivity analyses including full term pregnancies only $(\mathrm{N}=152,202)$. All findings with respect to first births were very similar in analyses including all women with a first birth (but not necessarily second, $\mathrm{N}=440,639)$. Analyses were performed using SAS 9.3 (SAS Institute Inc., Cary, NC). The study was approved by the regional ethics board in Umeå (Dnr 2010-157-31 Ö) 


\section{BMI before the first and second pregnancy}

BMI1 was similar across education groups, despite high-educated women having their first birth at a mean age $\sim 3.5$ and $\sim 5.8$ years older than intermediate and low-educated women, respectively (Figure 1). Adjusting for age at first birth, low and intermediate-educated women had markedly increased odds of overweight and obesity before the first pregnancy, and also increased odds of underweight status (Supplementary File 2). These differences were only marginally attenuated following adjustment for smoking, indicating that smoking status accounts for only a small part of the association between education and weight status.

Fig 1 Descriptive figure showing mean body mass index (BMI) measured at 4 time points (before the first pregnancy, at first delivery, before the second pregnancy and at the second delivery), stratified by women's education level $(\mathrm{N}=163$ 352).

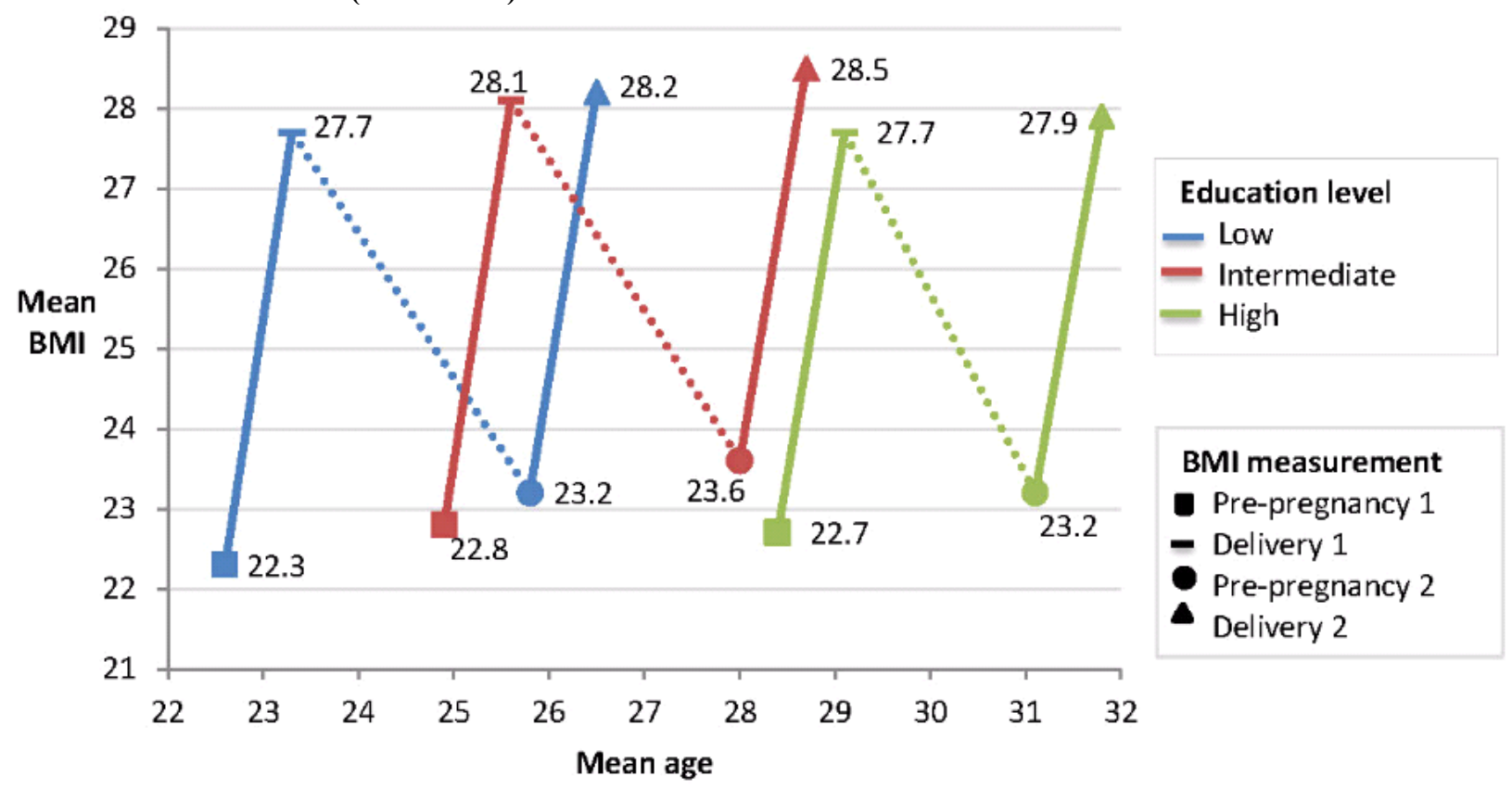

BMI at all 4 time points was significantly associated with education level ( $\mathrm{p}<0.0001)$. Education level measured near the time of the index pregnancy: Low - primary and lower secondary $\leq 10$ years, Intermediate upper secondary $\leq 13$ years, High - post secondary. Note: The dotted line represents the time period between the first delivery and before the second pregnancy, time for which we do not have weight information

Lower education was also associated with a greater BMI change between pregnancies (a mean absolute increase per year of $+0.27 \mathrm{~kg} / \mathrm{m}^{2}$ among low-educated, $+0.21 \mathrm{~kg} / \mathrm{m}^{2}$ among intermediate-educated and $+0.16 \mathrm{~kg} / \mathrm{m}^{2}$ among high-educated women). This meant that the education gradient in the odds of overweight and obesity had grown even steeper by the start of the second pregnancy ( $\mathrm{p}<0.0001$ for interaction, Supplementary File 2$)$.

Finally, the magnitude of the association between education and BMI change was moderated by GWG1 ( $p<0.0001$, Figure 2). Specifically, the relative difference in BMI change between education groups was greater among women who gained weight excessively during their first pregnancy than among women gaining weight adequately or inadequately (Figure 2). 
Fig 2 Mean change in body mass index (BMI) between the first and second pregnancy by education level, stratified by gestational weight gain in the first pregnancy $(\mathrm{N}=163$ 352). The figure shows the additional increase in BMI between pregnancies among the lower educated women, compared to high-educated women (reference group).

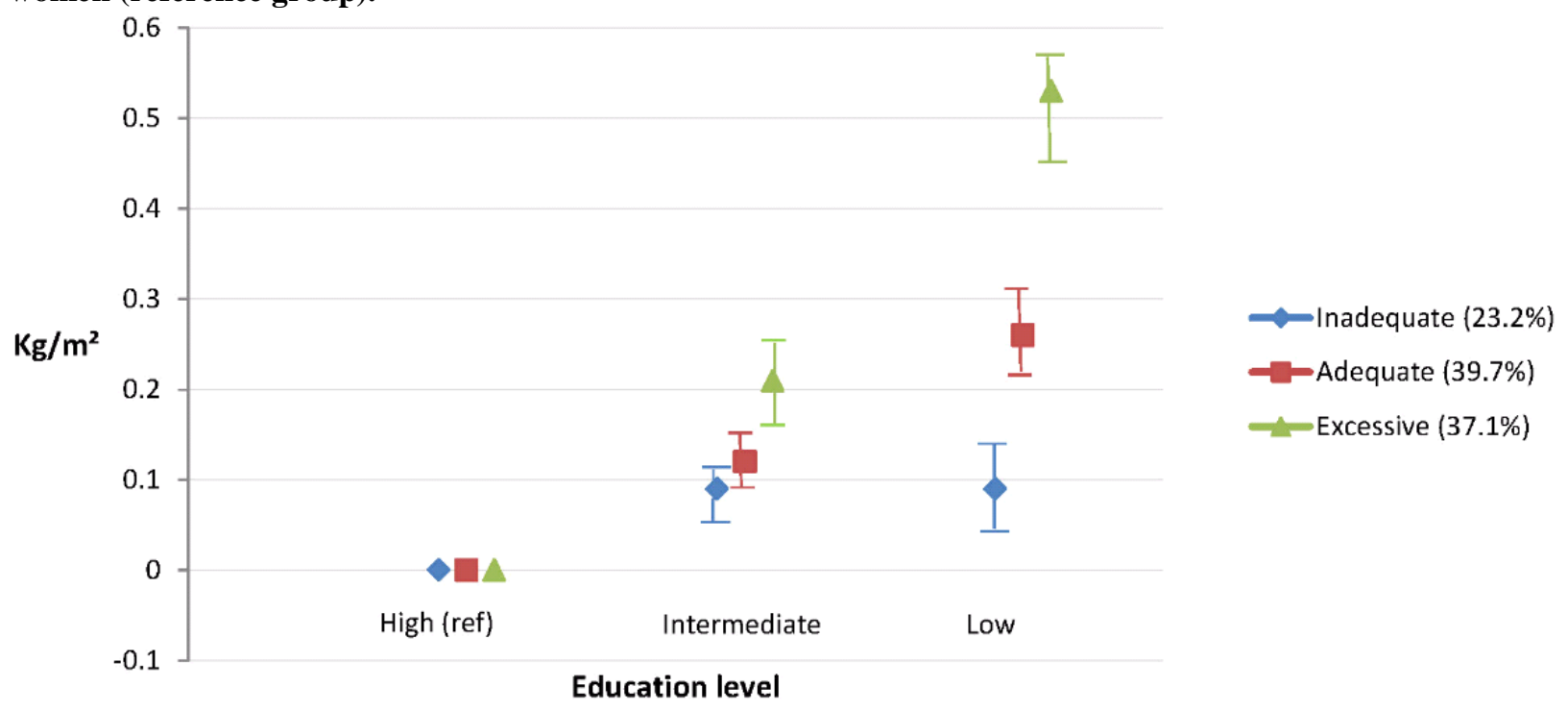

Education level was measured near the time of the first pregnancy: Low - primary and lower secondary $\leq 10$ years, Intermediate - upper secondary $\leq 13$ years, High - post secondary. GWG is based on the Institute of Medicine's guidelines for BMI specific weight gain in pregnancy. Note: Analysis adjusted for birth interval between child 1 and 2, own age and birth year. Significant interaction found between education and gestational weight gain $(\mathrm{p}<0.0001)$

\section{GWG in the first and second pregnancy}

The proportion of women with adequate GWG1 and GWG2 was slightly higher among underweight than healthy weight women, and markedly higher among healthy weight than overweight or obese women (Table 2 and Figure 3 ). 
Fig 3 Proportion of women gaining weight inadequately, adequately and excessively in each pregnancy, stratified by pre-pregnancy weight status. The figure shows a large proportion of overweight and obese women gaining weight excessively in both pregnancies, as well as a considerable proportion of underweight and healthy weight women gaining weight inadequately in both pregnancies.

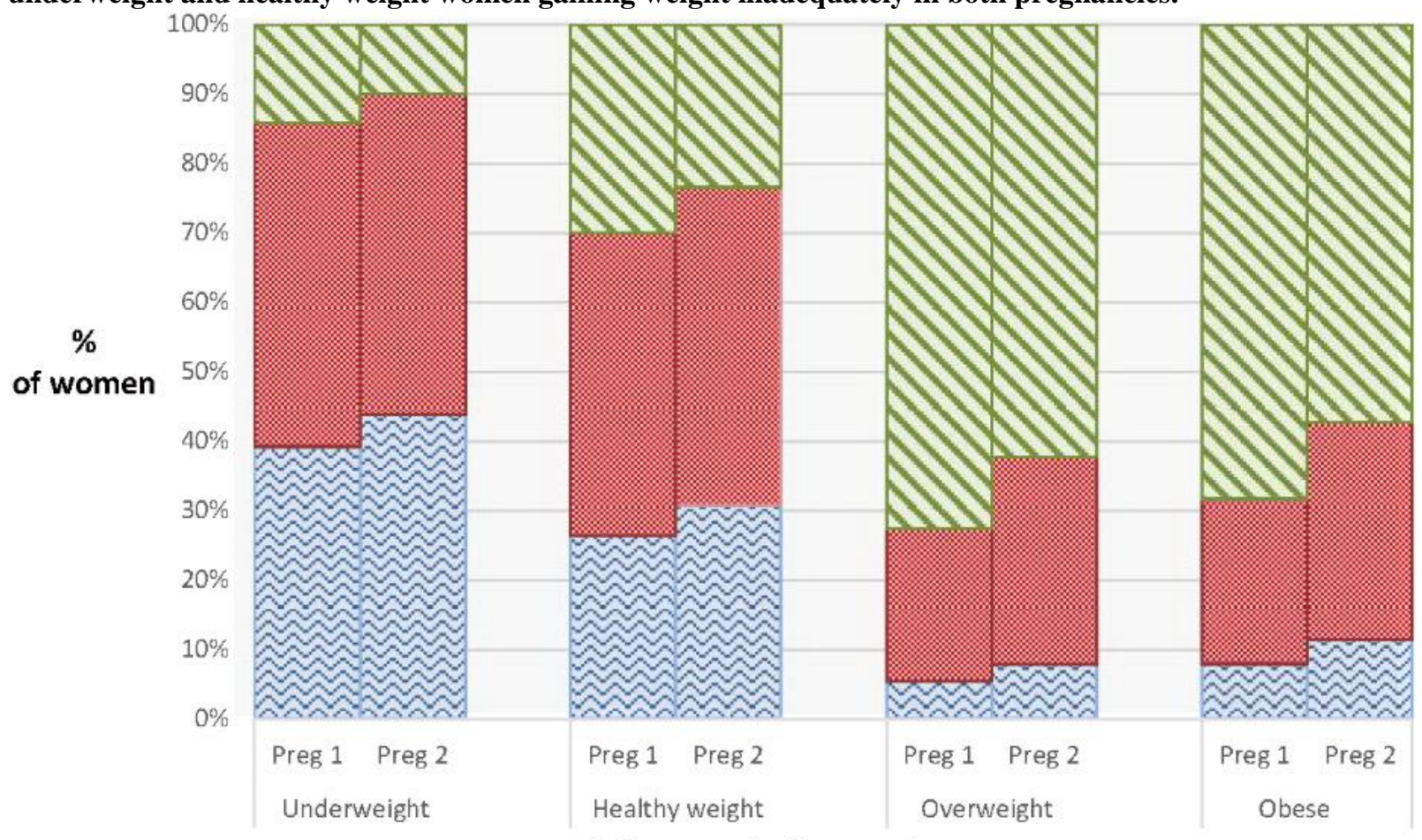

Weight status before each pregnancy

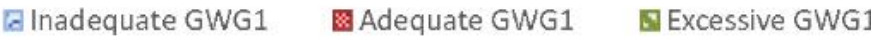

Preg1=pregnancy 1, Preg2= pregnancy $2 . \mathrm{GWG}=$ Gestational weight gain is based on the Institute of Medicine's guidelines for BMI specific weight gain in pregnancy 
Table 2: Bivariate association between education and gestational weight gain in first (GWG1) and second pregnancy (GWG2), among Swedish women with a first and second singleton birth between 1982-2010. Results stratified by weight status before the index pregnancy $(\mathrm{N}=163352)$

\begin{tabular}{|c|c|c|c|c|c|c|c|c|c|c|}
\hline \multirow[b]{3}{*}{$\begin{array}{l}\text { Education*stratifie } \\
\text { d by weight status }\end{array}$} & \multicolumn{10}{|c|}{ Gestational weight gain ${ }^{a}$} \\
\hline & \multicolumn{5}{|c|}{$1^{\text {st }}$ pregnancy: GWG1 } & \multicolumn{5}{|c|}{$2^{\text {nd }}$ pregnancy: GWG2 } \\
\hline & $\mathrm{N}$ & $\begin{array}{l}\text { Inadequate } \\
(\%)\end{array}$ & $\begin{array}{c}\text { Adequate } \\
(\%)\end{array}$ & $\begin{array}{c}\text { Excessiv } \\
\mathrm{e} \\
(\%)\end{array}$ & p-value & $\mathrm{N}$ & $\begin{array}{c}\text { Inadequate } \\
(\%)\end{array}$ & $\begin{array}{c}\text { Adequate } \\
(\%)\end{array}$ & $\begin{array}{c}\text { Excessiv } \\
\mathrm{e} \\
(\%)\end{array}$ & p-value \\
\hline Underweight & & & & & $<0.0001$ & & & & & $<0.0001$ \\
\hline High & 2102 & 44.7 & 46.1 & 9.2 & & 1967 & 47.4 & 44.6 & 8.0 & \\
\hline Intermediate & 4799 & 37.7 & 47.9 & 14.4 & & 3938 & 42.7 & 47.4 & 9.9 & \\
\hline Low & 2602 & 37.7 & 44.6 & 17.7 & & 1929 & 43.3 & 44.6 & 12.1 & \\
\hline Healthy weight $^{\mathrm{b}}$ & & & & & $<0.0001$ & & & & & $<0.0001$ \\
\hline High & 40273 & 28.3 & 46.5 & 25.2 & & 39651 & 31.8 & 47.4 & 20.8 & \\
\hline Intermediate & 61528 & 25.4 & 43.0 & 31.6 & & 55802 & 30.1 & 45.5 & 24.4 & \\
\hline Low & 20441 & 25.8 & 39.5 & 34.7 & & 16560 & 30.8 & 42.6 & 26.6 & \\
\hline Overweight & & & & & $<0.0001$ & & & & & $<0.0001$ \\
\hline High & 7430 & 5.1 & 22.5 & 72.4 & & 10058 & 6.4 & 30.0 & 63.6 & \\
\hline Intermediate & 13457 & 5.1 & 22.1 & 72.8 & & 17424 & 7.8 & 30.0 & 62.2 & \\
\hline Low & 3896 & 7.2 & 20.9 & 71.9 & & 4913 & 10.5 & 28.7 & 60.8 & \\
\hline Obese & & & & & 0.17 & & & & & 0.0002 \\
\hline$\overline{\text { High }}$ & 1777 & 7.5 & 24.0 & 68.5 & & 2784 & 9.6 & 30.0 & 60.4 & \\
\hline Intermediate & 4010 & 7.7 & 23.4 & 68.9 & & 6533 & 11.9 & 31.5 & 56.6 & \\
\hline Low & 1037 & 9.7 & 24.1 & 66.2 & & 1793 & 12.2 & 33.3 & 54.5 & \\
\hline
\end{tabular}

$\mathrm{GWG}=$ Gestational weight gain. *Education level near the time of index pregnancy: Low - primary and lower secondary $\leq 10$ years, Intermediate - upper secondary $\leq 13$ years, High - post secondary

aBMI-specific gestational weight gain, classified by IOM criteria and NRC. 'Healthy weight refers to the WHO BMI weight status category of 'normal weight', i.e. with BMI of $18.50-24.99 \mathrm{~kg} / \mathrm{m}^{2}$. 
In the second pregnancy, a smaller proportion of women gained weight excessively, while a larger proportion of women gained weight inadequately or adequately (Table 2). Inadequate weight gain was particularly striking among underweight and healthy weight women; this was observed in $\sim 40 \%$ of underweight and $\sim 30 \%$ of healthy weight women in both pregnancies. Compared to WHO recommended birth intervals, ${ }^{35}$ a longer interval was associated with increased odds of excessive GWG2 among healthy and overweight women, while a shorter interval was associated with decreased odds of excessive GWG2 (Table 3). A shorter interval was also associated with increased odds of inadequate GWG2 among healthy and underweight women (Table 3).

\section{Social patterning of GWG}

Among healthy weight women there was an association between increasing education and a decreased proportion of excessive GWG1 and GWG2 (Table 2). These associations were attenuated but remained highly significant after adjusting for maternal BMI (continuous separate results not shown); estimates further marginally attenuated after adjusting for maternal smoking (Table 3, Model 2) and birth interval (Table 3, Model 3). Overall, these associations were stronger in the first pregnancy $(\mathrm{p}<0.0001$ for interaction, Table 3$)$. 
Table 3: Association between education and gestational weight gain in the first and second pregnancy, among Swedish women with a first and second singleton birth between 1982-2010. Odds ratios and $95 \%$ CI from multinomial regression analysis $(\mathrm{n}=163352)$

\begin{tabular}{|c|c|c|c|c|c|c|c|c|c|c|c|c|}
\hline \multirow{4}{*}{$\begin{array}{l}\text { Education }^{\mathrm{a}} \\
\text { stratified by } \\
\text { weight status }\end{array}$} & \multicolumn{12}{|c|}{ IOM gestational weight gain ${ }^{b}$ (adequate GWG as reference) } \\
\hline & \multicolumn{6}{|c|}{ Inadequate } & \multicolumn{6}{|c|}{ Excessive } \\
\hline & \multicolumn{2}{|c|}{ Model 1} & \multicolumn{2}{|c|}{ Model 2} & \multicolumn{2}{|c|}{ Model 3} & \multicolumn{2}{|c|}{ Model 1} & \multicolumn{2}{|c|}{ Model 2} & \multicolumn{2}{|c|}{ Model 3} \\
\hline & OR & $95 \% \mathrm{CI}$ & OR & $95 \%$ CI & OR & $95 \% \mathrm{CI}$ & OR & $95 \% \mathrm{CI}$ & OR & $95 \%$ CI & OR & $95 \% \mathrm{CI}$ \\
\hline \multicolumn{13}{|l|}{$\underline{1}^{\text {st }}$ Pregnancy } \\
\hline \multicolumn{13}{|l|}{ Underweight } \\
\hline High (Ref) & 1.00 & & 1.00 & & & & 1.00 & & 1.00 & & & \\
\hline Intermediate & 0.85 & $0.76,0.96$ & 0.86 & $0.77,0.97$ & & & 1.35 & $1.12,1.63$ & 1.32 & $1.09,1.60$ & & \\
\hline Low & 0.94 & $0.82,1.09$ & 0.97 & $0.84,1.13$ & & & 1.68 & $1.35,2.08$ & 1.59 & $1.27,1.98$ & & \\
\hline \multicolumn{13}{|c|}{ Healthy weight ${ }^{\mathrm{c}}$} \\
\hline High(Ref) & 1.00 & & 1.00 & & & & 1.00 & & 1.00 & & & \\
\hline Intermediate & 0.97 & $0.94,1.00$ & 0.97 & $0.93,0.99$ & & & 1.26 & $1.22,1.30$ & 1.22 & $1.18,1.26$ & & \\
\hline Low & 1.06 & $1.02,1.12$ & 1.05 & $0.99,1.10$ & & & 1.44 & $1.38,1.51$ & 1.36 & $1.30,1.43$ & & \\
\hline \multicolumn{13}{|l|}{ Overweight } \\
\hline High (Ref) & 1.00 & & 1.00 & & & & 1.00 & & 1.00 & & & \\
\hline Intermediate & 0.97 & $0.84,1.13$ & 0.95 & $0.81,1.10$ & & & 0.96 & $0.89,1.03$ & 0.98 & $0.91,1.05$ & & \\
\hline Low & 1.42 & $1.17,1.73$ & 1.36 & $1.11,1.66$ & & & 0.97 & $0.87,1.08$ & 1.00 & $0.90,1.05$ & & \\
\hline \multicolumn{13}{|l|}{ Obese } \\
\hline High (Ref) & 1.00 & & 1.00 & & & & 1.00 & & 1.00 & & & \\
\hline Intermediate & 0.95 & $0.74,1.21$ & 0.89 & $0.69,1.14$ & & & 0.99 & $0.86,1.14$ & 1.03 & $0.89,1.19$ & & \\
\hline Low & 1.03 & $0.74,1.44$ & 0.94 & $0.67,1.33$ & & & 0.92 & $0.75,1.12$ & 0.97 & $0.79,1.19$ & & \\
\hline \multicolumn{13}{|c|}{$\underline{2}^{\text {nd }}$ Pregnancy } \\
\hline \multicolumn{13}{|c|}{ Underweight } \\
\hline High (Ref) & 1.00 & & 1.00 & & 1.00 & & 1.00 & & 1.00 & & 1.00 & \\
\hline Intermediate & 0.89 & $0.79,1.00$ & 0.89 & $0.79,1.01$ & 0.91 & $0.81,1.03$ & 1.08 & $0.87,1.34$ & 1.04 & $0.84,1.30$ & 1.01 & $0.81,1.26$ \\
\hline Low & 0.97 & $0.83,1.12$ & 0.96 & $0.82,1.12$ & 0.99 & $0.85,1.16$ & 1.31 & $1.02,1.68$ & 1.21 & $0.93,1.58$ & 1.17 & $0.89,1.52$ \\
\hline \multicolumn{13}{|c|}{ Child 1-2intervald (months) $^{\text {(m) }}$} \\
\hline$<27$ & & & & & 1.30 & $1.16,1.46$ & & & & & 0.87 & $0.72,1.06$ \\
\hline 27-36 (Ref) & & & & & 1.00 & & & & & & 1.00 & \\
\hline $36.1-68$ & & & & & 0.97 & $0.85,1.10$ & & & & & 1.12 & $0.92,1.38$ \\
\hline$>68$ & & & & & 1.01 & $0.77,1.32$ & & & & & 1.13 & $0.73,1.74$ \\
\hline \multicolumn{13}{|l|}{ Healthy weight ${ }^{\mathrm{c}}$} \\
\hline High (Ref) & 1.00 & & 1.00 & & 1.00 & & 1.00 & & 1.00 & & 1.00 & \\
\hline Intermediate & 1.04 & $1.01,1.08$ & 1.02 & $0.98,1.05$ & 1.03 & $1.00,1.06$ & 1.17 & $1.13,1.21$ & 1.14 & $1.10,1.18$ & 1.10 & $1.06,1.14$ \\
\hline
\end{tabular}




\begin{tabular}{|c|c|c|c|c|c|c|c|c|c|c|c|c|}
\hline Low & 1.22 & $1.16,1.28$ & 1.13 & $1.08,1.19$ & 1.15 & $1.09,1.21$ & 1.32 & $1.26,1.39$ & 1.29 & $1.22,1.35$ & 1.22 & $1.16,1.28$ \\
\hline \multicolumn{13}{|c|}{ Child 1-2interval (months) } \\
\hline$<27$ & & & & & 1.20 & $1.16,1.25$ & & & & & 0.87 & $0.84,0.91$ \\
\hline $27-36$ (Ref) & & & & & 1.00 & & & & & & 1.00 & \\
\hline $36.1-68$ & & & & & 0.98 & $0.94,1.02$ & & & & & 1.16 & $1.12,1.21$ \\
\hline$>68$ & & & & & 1.06 & $1.00,1.12$ & & & & & 1.31 & $1.23,1.40$ \\
\hline \multicolumn{13}{|l|}{ Overweight } \\
\hline High (Ref) & 1.00 & & 1.00 & & 1.00 & & 1.00 & & 1.00 & & 1.00 & \\
\hline Intermediate & 1.23 & $1.10,1.37$ & 1.15 & $1.03,1.29$ & 1.15 & $1.03,1.29$ & 0.93 & $0.88,0.98$ & 0.95 & $0.89,1.01$ & 0.93 & 0.88, 0.99 \\
\hline Low & 1.75 & $1.51,2.02$ & 1.51 & $1.30,1.76$ & 1.51 & $1.30,1.76$ & 0.87 & $0.79,0.94$ & 0.92 & $0.84,1.00$ & 0.90 & $0.82,0.98$ \\
\hline \multicolumn{13}{|c|}{ Child 1-2interval ${ }^{d}$ (months) } \\
\hline$<27$ & & & & & 1.09 & $0.97,1.22$ & & & & & 0.85 & $0.79,0.90$ \\
\hline $27-36$ (Ref) & & & & & 1.00 & & & & & & 1.00 & \\
\hline $36.1-68$ & & & & & 0.92 & $0.81,1.04$ & & & & & 1.03 & $0.96,1.10$ \\
\hline$>68$ & & & & & 1.11 & $0.93,1.32$ & & & & & 1.13 & $1.02,1.25$ \\
\hline \multicolumn{13}{|l|}{ Obese } \\
\hline High (Ref) & 1.00 & & 1.00 & & 1.00 & & 1.00 & & 1.00 & & 1.00 & \\
\hline Intermediate & 1.22 & $1.04,1.44$ & 1.11 & $0.93,1.31$ & 1.10 & $0.92,1.30$ & 0.96 & $0.87,1.07$ & 0.96 & $0.87,1.07$ & 0.95 & $0.86,1.06$ \\
\hline Low & 1.30 & $1.05,1.61$ & 1.10 & $0.87,1.38$ & 1.08 & $0.86,1.37$ & 0.94 & $0.82,1.08$ & 0.95 & $0.82,1.10$ & 0.93 & $0.81,1.08$ \\
\hline \multicolumn{13}{|c|}{ Child 1-2interval (months) $^{\text {(m) }}$} \\
\hline$<27$ & & & & & 1.01 & $0.84,1.20$ & & & & & 0.99 & $0.88,1.10$ \\
\hline $27-36$ (Ref) & & & & & 1.00 & & & & & & 1.00 & \\
\hline $36.1-68$ & & & & & 0.94 & $0.79,1.13$ & & & & & 0.93 & $0.83,1.04$ \\
\hline$>68$ & & & & & 1.12 & $0.88,1.42$ & & & & & 1.13 & $0.96,1.32$ \\
\hline
\end{tabular}

$\mathrm{CI}=$ confidence intervals, $\mathrm{GWG}=$ gestational weight gain, $\mathrm{IOM}=$ Institute of Medicine, $\mathrm{OR}=\mathrm{odds}$ ratio, Ref= reference group

Model 1: adjusted for birth year of index child and woman's age, Model 2: Model 1+ BMI and smoking at index pregnancy, Model 3: Model $2+$ birth interval between child 1 and 2 .

Model 1 - overall interaction between education and parity was significant $(\mathrm{p}<0.0001)$. Interaction stratified by pre-pregnancy BMI: underweight $\mathrm{p}=0.24$, healthy weight $\mathrm{p}<0.0001$, overweight $\mathrm{p}=0.04$, obese $\mathrm{p}=0.19$.

${ }^{a}$ Education level at the time of the index pregnancy: Low - primary and lower secondary $\leq 10$ years, Intermediate - upper secondary $\leq 13$ years, High - post secondary

${ }^{\mathrm{b}}$ BMI-specific gestational weight gain, classified by IOM criteria and NRC. Adequate gestational weight gain as the reference.

${ }^{\mathrm{c}}$ Healthy weight refers to the WHO BMI weight status category of 'normal weight', i.e. with BMI of $18.50-24.99 \mathrm{~kg} / \mathrm{m}^{2}$.

${ }^{\mathrm{d}}$ Based on the WHO recommendation of a birth to pregnancy interval of 18-27 months after a live birth (equivalent to a 27-36 month birth interval) Results in bold indicate statistical significance at the 0.05 level. 
Higher education also predicted decreased odds of excessive GWG1 and GWG2 among underweight women (Table 2, Table 3). There was again a trend towards a stronger effect in the first pregnancy, but this was not significant $(\mathrm{p}=0.24)$.

By contrast, in regression analyses among overweight and obese women, the education gradient in excessive GWG showed a trend in the opposite direction (though nonsignificant among obese women, Table 3); that is, there was a trend towards lower odds of excessive GWG among low-educated overweight or obese women. Low-educated overweight women also had increased odds of inadequate GWG1 and GWG2, compared to high-educated women (Table 3, Model 2). Among overweight women, the effect of education on $\mathrm{GWG}$ was stronger in the first pregnancy ( $\mathrm{p}=0.04$ for interaction).

\section{$\underline{\text { Discussion }}$}

Among women in Sweden, we found that those with a lower education were more likely to start their first and second pregnancy at an unhealthy weight; these women also experienced a greater increase in BMI between pregnancies. The education gradient for change in BMI was particularly large among women who had experienced the risk factor of gaining weight excessively in the first pregnancy. We also found that, among women with a healthy pre-pregnancy weight status, those with a lower education were in both pregnancies more likely to experience excessive GWG. However, this educational gradient in excessive GWG was generally non-significant among women who started their pregnancy overweight or obese, and moreover the trend was consistently in the opposite direction. Thus, higher education appeared not to be protective against excessive GWG among overweight/obese women.

The protective association between higher education and pre-pregnancy weight status supports previous findings focused on first pregnancies among Swedish women. ${ }^{25}$ In our study, BMI1 and BMI2 were very similar between education groups, despite the fact that the average age at first birth was considerably older among high-educated women $(\sim 3.5$ and $\sim 5.8$ years older). This is important from a public health perspective, underlining that increasing BMI is not solely determined by age and remains a modifiable maternal and neonatal risk factor.

The inverse association found for education and BMI change between pregnancies is similar to other studies of education and postpartum weight retention ${ }^{11,20}$ and long-term BMI. ${ }^{9,27,28}$ This educational gradient in BMI change amplified the pre-existing gradient in overweight/obesity, generating an educational gradient in overweight/obesity that was even stronger in the second pregnancy than the first (even after adjusting for birth interval). This finding highlights chains of interacting risks that may magnify existing social inequalities over time, as does our finding that the educational gradient in BMI change was particularly steep among women with excessive GWG1.

Consistent with evidence of excessive GWG accelerating overweight/obesity development in women, ${ }^{7,8}$ we found increased odds of overweight/obesity before the second pregnancy among women with excessive GWG in the first pregnancy. As weight 
gain is largely a modifiable risk factor, accurate information and implementation of existing guidelines may considerably improve GWG outcomes. Although accurate advice in itself may not be enough to assist women to gain weight adequately, ${ }^{36}$ being advised to gain too much weight is associated with excessive GWG. ${ }^{37}$ This may be due to practitioners being unaware of current guidelines ${ }^{38}$ or advising women incorrectly, particularly overweight/obese women. ${ }^{39}$ Ensuring wide access to up-to-date guidelines may provide women (especially low educated women) the opportunity to set a healthy, weight-status-appropriate GWG target. Similar to a U.S. study, ${ }^{14}$ we found a higher proportion of women gaining weight adequately in the second pregnancy, compared to the first. However it remains of clinical importance that $\sim 40 \%$ of underweight and $\sim 30 \%$ of healthy weight women gained inadequately in both pregnancies.

Among healthy and underweight women, we found a protective association between education and odds of excessive GWG in the first pregnancy. This accords with results among healthy weight women in a smaller Swedish study of first births. ${ }^{25}$ Possible explanations for this association include improved diet/physical activity patterns, greater compliance to medical instruction, better access to information and earlier weight trajectories, as well as personality characteristics and reinforced social norms among higher-educated women. The potential mediating/moderating role of behavioural factors such as smoking, diet and physical activity on weight gain in pregnancy should be addressed in future studies. Also of interest would be investigation of whether/how the associations with women's current educational level may reflect differences in women's growth trajectories and health or personality characteristics emerging earlier during their life course.

By contrast, the protective effect of education on excessive GWG was absent among overweight and obese women. Indeed, if anything, the trend was in the opposite direction, although it only reached significance for overweight women in the second pregnancy. The reason for this absence (or even reversal) of the education gradient is unclear; speculatively, it may be that overweight/obese women are a more closely monitored group, particularly if they experience excessive GWG in the first pregnancy. In any case, these results suggest that maintaining a healthy weight during pregnancy may be a challenge for women from all educational groups, particularly if the woman's pre-pregnancy BMI is high.

Finally, a shorter than WHO recommended birth interval ${ }^{35}$ was associated with increased odds of inadequate GWG2 among healthy and underweight women. Increased odds of excessive GWG2 were found among healthy and overweight women with a longer than recommended birth interval. This suggests that women with a shorter and longer than recommended birth interval may be potentially at-risk and require additional monitoring and advice.

\section{Strengths and limitations}

While using high-quality register data is a strength, potential limitations include a large proportion of women excluded due to missing data, partly due to administrative reasons 
(data not collected during two calendar years). Reassuringly, the characteristics of excluded women were very similar to women with complete data. Nevertheless, the potential for some selection bias remains. For example, a relatively high proportion of women lacked data on GWG, and it is possible that women appearing to gain weight appropriately would be less closely monitored and as such be missing GWG data. Additionally, we cannot exclude possible measurement error due to using self-reported data on height and weight, although both are found reasonable for epidemiological studies. ${ }^{40}$

While a steady increase in prevalence of pre-pregnancy overweight/obesity has been observed over time in Sweden, there was an unexpectedly large increase from 1989 to 1992, which we suspect is a possible artefact of changes in BMI measurement before and after 1992. While this is unlikely to vary by education level and significantly influence our results, all models were minimally adjusted for birth year of the child to account for this. Finally, it is arguably a limitation that we applied the 2009 IOM guidelines to data collected in Sweden and between 1982 and 2010, i.e., prior to when the guidelines were written. We made this decision based on i) an absence of Swedish guidelines and ii) a desire to define weight gain in relation to what is healthy for mother and child, even if this does not necessarily match the advice women received.

\section{$\underline{\text { Conclusion }}$}

Our results show a protective effect of education for starting pregnancy at a healthy weight; avoiding a high BMI increase between pregnancies; and (among healthy-weight women) avoiding excessive GWG. While assisting women to start their first pregnancy at a healthy weight should remain a priority, targeting GWG as a key modifiable risk factor on the path to overweight/obesity should also be considered; namely, focusing on achieving GWG within the IOM guidelines, as well as returning to a healthy postpartum weight within a reasonable time frame. Our research identifies women who may be at particular increased risk of later overweight/obesity. This includes low educated women who gain weight excessively in the first pregnancy, and are therefore particularly likely to experience a large BMI increase between pregnancies. It also includes overweight/obese women of any educational group, who are particularly likely to experience excessive GWG during pregnancy.

Pregnancy is a time when women are both concerned about their child's health and heavily engaged with health professionals; as such, it provides a unique opportunity for lifestyle modifications which may prevent overweight/obesity and improve long-term health outcomes for mother and child. Our results could inform the design of both universal and targeted interventions, including supporting women to start their pregnancy at a healthy BMI, to gain weight appropriately and to return to a healthy pre-pregnancy $\mathrm{BMI}$ in a reasonable time.

\section{Conflict of interest}

None 


\section{Funding and acknowledgements}

This work was supported by the Swedish Research Council (grant numbers 2008-7483, 2009-3146 and 2013-5474) and the Swedish Research Council for Health, Working Life and Welfare (grant numbers 2006-1518, 2013-1084, 2013-1850 and 2014-2693). NH is supported by the Australian Postgraduate Award scholarship. GM is supported by the Australian Research Council Future Fellowship (FT120100812). The Umeå SIMSAM Lab data infrastructure used in this study was developed with support from the Swedish Research Council (2008-7491) and by strategic support from Umeå University.

\section{$\underline{\text { References }}$}

1. Novak M, Ahlgren C, Hammarström A. A life-course approach in explaining social inequity in obesity among young adult men and women Int J Obes (London) 2006;30(1):191-200.

2. Statistics Sweden (Statistika Centralbyrån). Living Conditions Survey (Undersökningarna av levnadsförhållanden). 2012. URL: http://www.scb.se/sv_/Hitta-statistik/Statistik-efteramne/Levnadsforhallanden/Levnadsforhallanden/Undersokningarna-avlevnadsforhallanden-ULFSILC/12202/2012A02B/Accessed Jul 2014.

3. Chaparro M, Ivarsson A, Koupil I, et al. Regional inequalities in pre-pregnancy overweight and obesity in Sweden, 1992, 2000, and 2010. Scand J Public Health 2015(May 6):pii: 1403494815579478. [Epub ahead of print].

4. Guelinckx I, Devlieger R, Beckers K, et al. Maternal obesity: pregnancy complications, gestational weight gain and nutrition Obes Rev 2008;9(2):140-50.

5. DeVader S, Neeley H, Myles T, et al. Evaluation of gestational weight gain guidelines for women with normal prepregnancy body mass index. Obstet Gynecol 2007;110(4):845-51.

6. Whitaker K, Young-Hyman D, Vernon M, et al. Maternal stress predicts postpartum weight retention. Matern Child Health J 2014;18(9):2209-17.

7. Amorim A, Rössner S, Neovius M, et al. Does excess pregnancy weight gain constitute a major risk for increasing long-term BMI? . Obesity (Silver Spring) 2007;15(5):1278-86.

8. Rooney B, Schauberger C. Excess pregnancy weight gain and long-term obesity: one decade later. Obstet Gynecol 2002;100(2):245-52.

9. Brown W, Hockey R, Dobson A. Effects of having a baby on weight gain. Am J Prev Med 2010;38(2):163-70.

10. Ball K, Brown W, Crawford D. Who does not gain weight? Prevalence and predictors of weight maintenance in young women. Int J Obes Relat Metab Disord 2002;26(12):1570-8.

11. Shrewsbury V, Robb K, Power C, et al. Socioeconomic differences in weight retention, weight related attitudes and practices in postpartum women. Matern Child Health J 2009;13(2):231-40. 
12. Lahmann P, Lissner L, Gullberg B, et al. Sociodemographic factors associated with long-term weight gain, current body fatness and central adiposity in Swedish women. Int J Obes Relat Metab Disord 2000;24(6):685-94.

13. Bastian L, West N, Corcoran C, et al. Number of children and the risk of obesity in older women. Prev Med 2005;40(1):99-104.

14. Gunderson E. Childbearing and obesity in women: Weight before, during and after pregnancy. Obstet Gynecol Clin North Am 2009;36(2):317-32.

15. Gunderson E, Murtaugh M, Lewis $C$, et al. Excess gains in weight and waist circumference associated with childbearing: The Coronary Artery Risk Development in Young Adults Study (CARDIA). Int J Obes Relat Metab Disord 2004;28(4):525-35.

16. Restall A, Taylor R, Thompson J, et al. Risk factors for excessive gestational weight gain in a healthy, nulliparous cohort. J Obes 2014;2014:148391.

17. Rode L, Kjaergaard H, Ottesen B, et al. Association between gestational weight gain according to body mass index and postpartum weight in a large cohort of Danish women. Matern Child Health J 2012;16(2):406-13.

18. Siega-Riz A, Herring A, Carrier K, et al. Sociodemographic, perinatal, behavioral, and psychosocial predictors of weight retention at 3 and 12 months postpartum. Obesity (Silver Spring) 2010;18(10):1996-2003.

19. Löf M, Hilakivi-Clarke L, Sandin S, et al. Effects of pre-pregnancy physical activity and maternal BMI on gestational weight gain and birth weight. Acta Obstet Gynecol Scand 2008;87(5):524-30.

20. Siega-Riz A, Deierlein A, Stuebe A. Implementation of the new Institute of Medicine gestational weight gain guidelines. J Midwifery Womens Health 2010;55(6):51219.

21. Gunderson E, Abrams B, Selvin S. The relative importance of gestational gain and maternal characteristics associated with the risk of becoming overweight after pregnancy. Int J Obes Relat Metab Disord 2000;24(12):1660-8.

22. Kac G, Benicio M, Velasquez-Melendez G, et al. Gestational weight gain and prepregnancy weight influence postpartum weight retention in a cohort of Brazilian women. J Nutr 2004;134(3):661-6.

23. Linné Y, Dye L, Barkeling B, et al. Long-Term Weight Development in Women: A 15-Year Follow-up of the Effects of Pregnancy. Obes Res 2004;12(7):1166-78.

24. Linné Y, Rössner S. Interrelationships between weight development and weight retention in subsequent pregnancies: the SPAWN study Acta Obstetricia Gynecologica Scandinavia 2003;82(4):318-25.

25. Holowko N, Mishra G, Koupil I. Social inequality in excessive gestational weight gain. Int J Obes (Lond) 2014;38(1):91-6.

26. Bjermo H, Lind S, Rasmussen F. The educational gradient of obesity increases among Swedish pregnant women: a register-based study. BMC Public Health 2015;Apr 1(15):315.

27. Ball K, Crawford D. Socioeconomic status and weight change in adults: a review. Soc Sci Med 2005;60(9):1987-2010.

28. Clarke P, O'Malley P, Johnston L, et al. Social disparities in BMI trajectories across adulthood by gender, race/ethnicity and lifetime socio-economic position: 19862004. Int J Epidemiol 2009;38(2):499-509. 
29. Huynh M, Borrell L, Chambers E. Maternal education and excessive gestational weight gain in New York city, 1999-2001: the effect of race/ethnicity and neighborhood socioeconomic status. Matern Child Health J 2014;18(1):138-45.

30. Ashley-Martin J, Woolcott C. Gestational weight gain and postpartum weight retention in a cohort of Nova Scotian women. Matern Child Health J 2014;18(8):1927-35.

31. Källén B, Källén K. Utvärdering av det svenska Medicinska födelseregistret (Evaluation of the Swedish Medical Birth Register): Socialstyrelsen, Epidemiologiskt Centrum (Swedish National Board of Health and Welfare, Centre of Epidemiology), 2002.

32. World Health Organization, Regional Office for Europe. Body Mass Index - BMI. 2015 URL: http://www.euro.who.int/en/health-topics/diseaseprevention/nutrition/a-healthy-lifestyle/body-mass-index-bmi Accessed Jan 2015.

33. Institute of Medicine (US) and National Research Council (US) Committee to Reexamine IOM Pregnancy Weight Guidelines; Rasmussen, KM, Yaktine, AL, editors. Weight Gain During Prenancy: Reexamining the Guidelines. Washington (DC): The National Academies Press (US); 2009. Report no. 9780309131131

34. Cedergren M. Effects of gestational weight gain and body mass index on obstetric outcome in Sweden Int J Gynaecol Obstet 2006;93(3):269-74.

35. Marston C. Report of a WHO Technical Consultation on Birth Spacing. Geneva, Switzerland: World Health Organisation, Department of Making Pregnancy Safer (MPS) \& Department of Reproductive Health and Research (RHR); 2005, 13-15 June.

36. Olson C, Strawderman M, Reed R. Efficacy of an intervention to prevent excessive gestational weight gain Am J Obstet Gynecol 2004;191(2):530-6.

37. Brawarsky P, Stotland N, Jackson R, et al. Pre-pregnancy and pregnancy related factors and the risk of excessive or inadequate gestational weight gain. Int $J$ Gynaecol Obstet 2005;91(2):125-31.

38. Moore Simas T, Waring M, Sullivan G, et al. Institute of medicine 2009 gestational weight gain guideline knowledge: survey of obstetrics/gynecology and family medicine residents of the United States. Birth 2013;40(4):237-46.

39. Phelan S, Jankovitz K, Hagobian T, et al. Reducing gestational weight gain. Women's Health 2011;7(6):641-61.

40. Spencer E, Appleby P, Davey G, et al. Validity of self-reported height and weight in 4808 EPIC-Oxford participants. Public Health Nutr 2002;5(4):561-5. 


\section{Supplementary file 1; Exclusion of women with implausible values for height, pre- pregnancy weight or gestational weight gain}

We excluded women with a height $\langle=70 \mathrm{~cm}$ or $>=200 \mathrm{~cm}$, pre-pregnancy weight of $<=34 \mathrm{~kg}$ or $\langle=200 \mathrm{~kg}$; GWG $>=41 \mathrm{~kg}$. Additionally we excluded implausible combinations of BMI and height: BMI $<16$ and height $>=180 \mathrm{~cm}$; BMI $>35$ and height $<130$; BMI $<12$. We further sequentially excluded 2,029 women with implausible values; 3 women with an inter-birth interval $<9$ months; 222 women with weight change per year between pregnancies greater than $15 \mathrm{~kg}$; and 1,804 women with GWG in the first or second pregnancy of less than $1 \mathrm{~kg}$ or greater than $35 \mathrm{~kg}$, consistent with an earlier analysis of Swedish data[1] and a population study which suggested that extremes in GWG may be related to uncommon pathologies[2].

1. Holowko N, Mishra G, Koupil I. Social inequality in excessive gestational weight gain. Int J Obes (Lond) 2014;38(1):91-6.

2. Mamun A, Callaway L, O'Callaghan M, et al. Associations of maternal pre-pregnancy obesity and excess pregnancy weight gains with adverse pregnancy outcomes and length of hospital stay. BMC Pregnancy Childbirth 2011;11(62). 


\section{Supplementary File 2: Association between education and weight status before the first and second pregnancy, among Swedish women with a first and second singleton birth between 1982-2010. Odds ratios and 95\% C.I. from multinomial regression analysis $(\mathrm{N}=163,352)$}

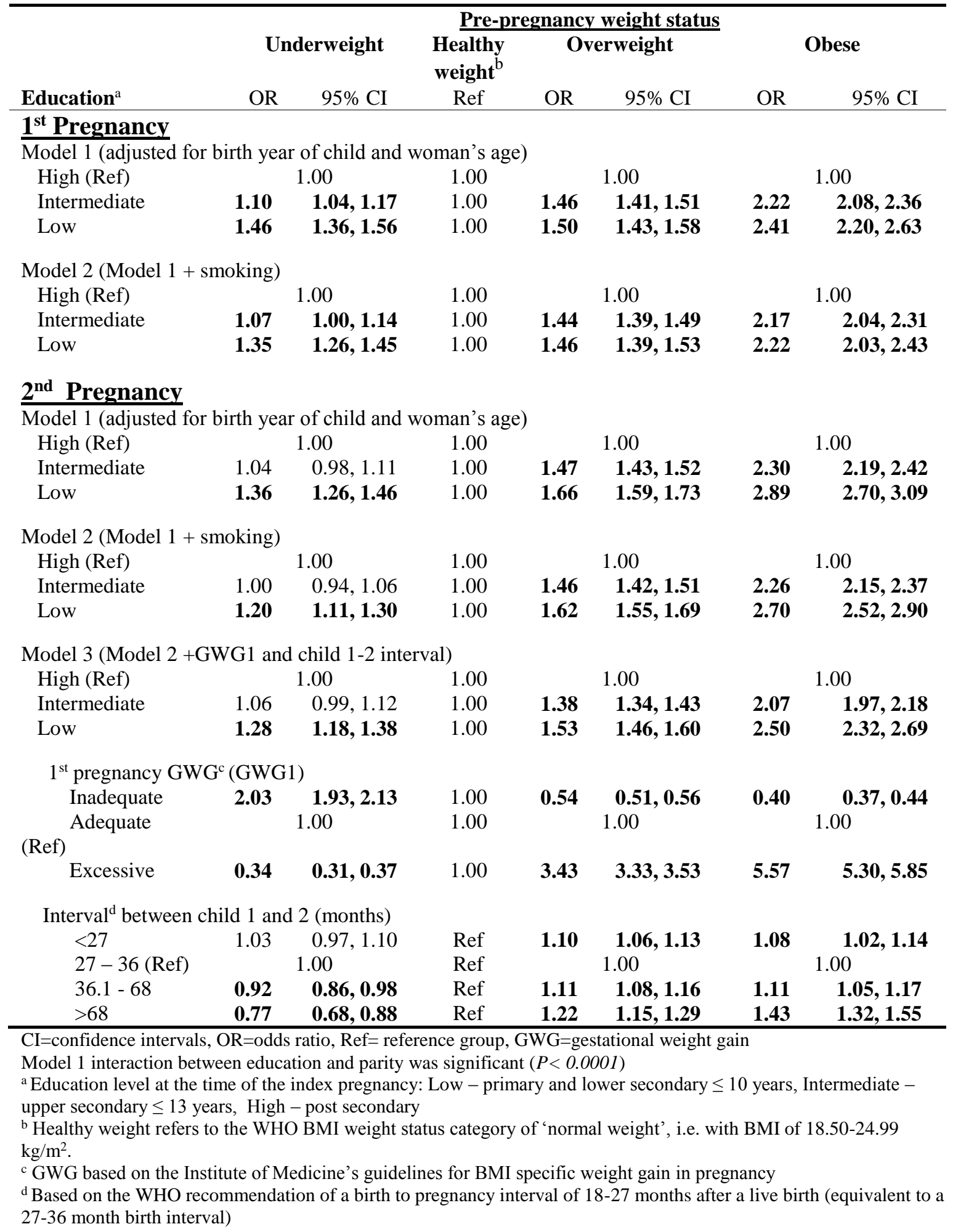

